\title{
Cytologic-Radiologic Correlation Using Transthoracic CT-Guided FNA for Lung and Mediastinal Masses: Our Experience
}

\author{
Sanjay Piplani, ${ }^{1}$ Rahul Mannan, ${ }^{1}$ Monika Lalit, ${ }^{2}$ Mridu Manjari, ${ }^{1}$ \\ Tejinder S. Bhasin, ${ }^{1}$ and Jasmin Bawa ${ }^{1}$ \\ ${ }^{1}$ Department of Pathology, Sri Guru Ram Das Institute of Medical Sciences \& Research, 24 Lane No. 5, Gopal Nagar, \\ Majitha Road, Amritsar, Punjab 143001, India \\ ${ }^{2}$ Department of Anatomy, Sri Guru Ram Das Institute of Medical Sciences \& Research, Amritsar, Punjab, India
}

Correspondence should be addressed to Sanjay Piplani; sanjaymikki@gmail.com

Received 11 June 2014; Accepted 14 September 2014

Copyright (C) 2014 Sanjay Piplani et al. This is an open access article distributed under the Creative Commons Attribution License, which permits unrestricted use, distribution, and reproduction in any medium, provided the original work is properly cited.

\begin{abstract}
Background and Objectives. Thoracic lesions account for various benign and malignant conditions. Of these lung carcinoma (mainly primary) is the most common carcinoma in the world. The present study was undertaken to know the pathological spectrum of thoracic lesions and to correlate cytoradiological findings. Materials and Methods. The present study was conducted in a tertiary care center of North India on 74 patients over an 18-month period. CT guided transthoracic FNAC (TTFNA) was carried out, and aspirates were drawn, examined, and compared with radiological diagnoses. Results. The diagnostic accuracy for FNA in the present study was calculated to be $95.94 \%$ (using cytology as the gold standard). The predominant lesion was malignancy (85.1\%), followed by suspicions of malignancy and inflammatory pathology ( $5.40 \%$ each). By cytology, the most common malignant lesion was adenocarcinoma (48\%) followed by squamous cell carcinoma (40\%), small cell carcinoma (8\%), and undifferentiated carcinoma (4\%). Cytoradiological correlation was found to be $89.2 \%$ in the present study. Conclusion. Present study thus concludes that TT FNA of thoracic lesions is a simple, safe, economically prudent technique associated with low morbidity and leading to quick and early diagnosis.
\end{abstract}

\section{Introduction}

Thoracic lesions include a large variety of benign and malignant conditions of lung, pleura, mediastinum, and vertebrae. Primary lung carcinoma is the most common carcinoma in the world today, comprising $12.6 \%$ of all the cancers and $17.8 \%$ of all the cancer deaths [1]. Lung is also a well-known site for metastatic tumors. In addition, the mediastinum can be involved with a variety of benign lesions as well as by primary and metastatic malignant tumor, many of which present as mediastinal masses [2,3]. Although clinical data, location, and radiological findings can narrow down the diagnostic possibilities, cytological diagnosis is warranted before initiating the specific treatment for malignant diseases [4].
Percutaneous CT-guided transthoracic fine needle aspiration cytology (TTFNA) is a well-established diagnostic method used in cytological evaluation of thoracic mass lesions. Currently TTFNA for lesions of the lungs and mediastinum is a widely practiced method, where the facilities of standard imaging techniques and cytopathology are available. This procedure provides a safe, rapid, and accurate diagnosis in patients having thoracic mass lesions [3-5]. In patients with lung cancer which is inoperable owing to local factors or the patient's general condition, FNAC confirms the diagnosis and reveals the tumor type [6].

The purpose of the present study was to know the pathological spectrum of thoracic lesions and to correlate the radiological findings with cytological findings obtained from CT-guided FNAC. 


\section{Material and Methods}

The present study was conducted on 74 patients who had thoracic mass lesions that were suspected to be neoplastic in most of the cases by chest radiographs and CT scan in the department of pathology, SGRDIMSR, Amritsar, from June 2010 to December 2011.

The procedure was carried out as an outpatient procedure in all the selected patients after explaining the risks and benefits. Informed consent was also obtained from every case. Detailed personal (especially tobacco habit) and occupational history was also taken.

Proper aseptic care was taken by cleaning the skin surface with povidone iodine before every FNAC. Aspiration was done using $21 \mathrm{G}, 88 \mathrm{~mm}$ long spinal needle attached to a $10 \mathrm{~mL}$ disposable syringe through percutaneous and transthoracic approaches. The lesion was identified in exact section by CT scan after the measurement of the site of entry of needle, route of needle, and distance between skin and the lesion on the CT scan monitor. Aspirates were smeared on clean glass slides, wet-fixed, or air-dried and stained by Papanicolaou (Pap), May-Grunwald Giemsa (MGG), and haematoxylin and eosin stains. All patients were watched carefully for the signs of pneumothorax and excessive bleeding. A followup X-Ray was performed four hours after the TTNAC to look for any such signs.

The slides were screened for adequacy of the aspirate and those with inadequate material were not included in the study for calculating results. The cytological diagnoses rendered by full consensus by three experienced cytopathologists were taken as final. The radiological opinion of each individual lesion was also recorded. Both cytological and radiological opinions were tabulated and compared statistically.

\section{Results}

The diagnostic accuracy was $95.94 \%$ considering cytological criteria as the standard. Most common age group affected was 4 th to 7 th decade $(83.7 \%)$ with a range of 32 years to 77 years. A male preponderance was noted in this study with a $\mathrm{M}: \mathrm{F}$ ratio of $2.08: 1$.

The predominant lesion found in the present study was malignancy in 63 cases $(85.1 \%)$, followed by suspicions of malignancy in four cases $(5.40 \%)$. Two cases each $(2.70 \%)$ were diagnosed as granulomatous and inflammatory lesions, respectively. The material was inadequate for interpretation in three cases (4\%). These cases were omitted from study for further calculations (Table 1).

Out of fifty four FNAC-proven cases of primary neoplasms of lung, forty three were males (79.6\%) and eleven were females (20.4\%). Hence, there was a significant male preponderance in primary neoplasms of lung with a $\mathrm{M}: \mathrm{F}$ ratio of $3.9: 1$ (Table 2).

On cytological typing of primary lesions, it was observed that the most common malignant lesion seen was adenocarcinoma in twenty four cases (44.5\%). Two of these were diagnosed as bronchoalveolar variant of adenocarcinoma. Squamous cell carcinoma was diagnosed as second most common lesion (twenty cases; $37.0 \%$ ) followed by small cell
TABLE 1: The demographic description of the study.

\begin{tabular}{|c|c|c|c|}
\hline Subject & Subheadings & $\begin{array}{c}\text { Total } \\
\text { number }\end{array}$ & Percentage \\
\hline \multirow{5}{*}{ Age } & Below 40 years & 07 & 9.46 \\
\hline & $40-49$ years & 15 & 20.27 \\
\hline & $50-59$ years & 34 & 45.95 \\
\hline & $60-69$ years & 13 & 17.56 \\
\hline & 70 years and above & 05 & 6.75 \\
\hline \multirow{2}{*}{ Sex } & Male & 50 & 67.50 \\
\hline & Female & 24 & 32.50 \\
\hline \multirow{3}{*}{ Type of lesions } & Lung mass & 71 & 95.90 \\
\hline & Mediastinal mass & 02 & 2.70 \\
\hline & Pleural mass & 01 & 1.40 \\
\hline \multirow{2}{*}{ History of smoking } & Smoker & 32 & 43.20 \\
\hline & Nonsmoker & 42 & 56.80 \\
\hline \multirow{2}{*}{$\begin{array}{l}\text { Radiological } \\
\text { diagnosis }\end{array}$} & Malignant & 69 & 93.20 \\
\hline & Benign & 05 & 06.80 \\
\hline \multirow{4}{*}{$\begin{array}{l}\text { Cytological } \\
\text { findings }\end{array}$} & Malignant & 63 & 85.10 \\
\hline & $\begin{array}{c}\text { Suspicious of } \\
\text { malignancy }\end{array}$ & 04 & 05.40 \\
\hline & Benign & 04 & 05.40 \\
\hline & Inadequate & 03 & 04.10 \\
\hline \multirow{2}{*}{ Sampling } & Adequate & 71 & 96 \\
\hline & Inadequate & 03 & 04 \\
\hline
\end{tabular}

carcinoma ( 4 cases; 7.4\%) and undifferentiated carcinoma (2 cases; $3.7 \%)$. Four cases (7.4\%) were reported as suspicious of malignancy owing to paucicellularity (Figure 1). These cases were kept under primary malignant lesions on cytology due to strong clinical and radiological opinion. These lesions could not be subtyped because of aforementioned paucicellularity (Table 2).

A difference in prevalence of primary lung lesions was noted between males versus female subpopulation. While adenocarcinoma was the most common primary lung lesion in females $(81 \%)$, squamous cell carcinoma was slightly more common than adenocarcinoma in males (18 cases of SCC; 15 cases of adenocarcinoma). Overall, adenocarcinoma, however, was the most common malignancy with a $\mathrm{M}: \mathrm{F}$ ratio of $1.2: 1$ (Tables 1 and 2).

While tabulating the association of neoplasms with tobacco usage, it was noted that thirty out of fifty patients presenting with primary lung lesions were smokers with all of them being males. Out of these thirty patients, squamous cell carcinoma (16 cases; $53.33 \%$ ) was the most common malignant subtype followed by adenocarcinoma (9 cases; $30 \%$ ), small cell carcinoma (4 cases; $13.33 \%$ ), and undifferentiated carcinoma (1 case; $3.33 \%$ ). There was, therefore, a strong predisposition to develop lung carcinoma among smokers and squamous cell carcinoma was the most common malignancy among smokers (Table 2).

Metastatic deposits (as secondary lung lesions) were seen in six females and four males $(\mathrm{M}: \mathrm{F}$ ratio- $1: 1.5)$. In half the cases $(50 \%)$, in male subjects, the primary lesion was located 
TABLE 2: Spectrum of lesions in the present study ${ }^{\dagger}$.

\begin{tabular}{lcc}
\hline Thoracic mass lesions & Cytological diagnosis & \\
\hline Malignant & Squamous cell carcinoma & Number \\
& Adenocarcinoma & 20 \\
$1^{\circ}$ Lung tumors & Small cell carcinoma & 24 \\
& Large cell carcinoma/undifferentiated & 04 \\
& Suspicious of malignancy & 04 \\
& Metastasis from breast & 02 \\
$2^{\circ}$ Lung tumors & Metastasis from cervix & 02 \\
& Metastasis from GIT & 02 \\
& Metastasis from oral cavity \\
Mediastinal tumors & Metastasis from vocal cord & 02 \\
Pleural tumors & Metastasis from thyroid \\
Benign & Non-Hodgkin's lymphoma & 01 \\
& Mesothelioma & 01 \\
\hline
\end{tabular}

${ }^{\dagger}$ Calculations have been done after excluding 03 cases which had inadequate material.

in oral cavity followed by one case each in vocal cord and gastrointestinal tract (GIT). On the other hand, frequency of primary was equal in female subjects, with 2 cases each metastasizing from breast, GIT, and cervix (Figure 2).

Extrapulmonary lesions from mediastinum were majorly of haematolymphoid origin and all were diagnosed as nonHodgkin's lymphoma (NHL). One case of mesothelioma in a 50-year-old male was also diagnosed.

No major complications were encountered in this study; however, one patient did complain of dyspnoea following the procedure.

Cytoradiological correlation was also attempted in the present study and it was found to be $89.2 \%$. In 8 cases out of 74, discrepancy was noted owing to 3 cases of inadequate material, 2 cases misdiagnosed as malignant on radiology, and 3 cases wrongly subtyped on radiology.

\section{Discussion}

CT assisted transthoracic FNA procedure not only is minimally invasive yielding quick and accurate diagnosis but also is economical and associated with low morbidity complaints. Other points in favour of FNA over open biopsy and core needle biopsy have high degree of sensitivity and specificity of this procedure in cases of malignancies. A review of thoracic FNA by a study conducted by C. J. R. Stewart and I. S. Stewart [7] revealed a specificity of $100 \%$ in cases of malignancies. FNA has also been shown to have a high degree of positive predictive value (99\%) in a large study [8]. A negative result, generally, is less reliable and most reports document a false negative rate of $10-20 \%$ for lung aspiration cytology. The reported sensitivity and diagnostic accuracy for benign and nonneoplastic lesions are not so high (40-70\%) [8-12] prompting many to recommend core needle biopsy to obtain a definitive diagnosis in benign conditions [11-14].
In the present study the male preponderance noted is consistent with the studies done by other researchers $[15,16]$.

In the study conducted, $84 \%$ of cases were diagnosed as non-small cell carcinomas, whereas small cell carcinomas were $12 \%$ of the primary lung lesions. This corroborates with the work done by other researchers who have reported an incidence of $70 \%$ and $20 \%$ in non-small cell and small cell carcinomas, respectively $[17,18]$.

Adenocarcinoma was the most common malignant lesion followed by squamous cell carcinoma on subtyping the nonsmall cell carcinomas. This is in concordance with recent work done by other researchers where adenocarcinoma has overtaken squamous cell carcinoma as the leading primary malignant neoplasm [17-19].

In metastatic lesions, adenocarcinoma and squamous cell carcinoma were seen in equal number of cases. The metastatic lesions in cases of males were predominantly located in the oral cavity and larynx which reflects the increased tobacco and alcohol habit in males. Primary tumors in metastatic lesions in females were expectedly located mainly in breast and cervix.

Unlike the work done by other researchers, inadequacy was not a big problem in our study (accounting for 3 cases; $4 \%)$ as the study employed the technique of immediate cytological assessment by means of rapid staining procedures and joint presence of both radiologists and pathologists which is recommended by various researchers. The reported rates of inadequacy in other studies range from 16 to $27 \%$ $[10,20-23]$.

Complications of TTFNA reported by various researchers were comprised of pain at the puncture site, pneumothorax, pulmonary haemorrhage, hemoptysis, implantation of the malignant cells in the needle tract, empyema, and bleeding into the chest wall. Pneumothorax is the most common complication with the occurrence rates varying from 3 to $57 \%$ 


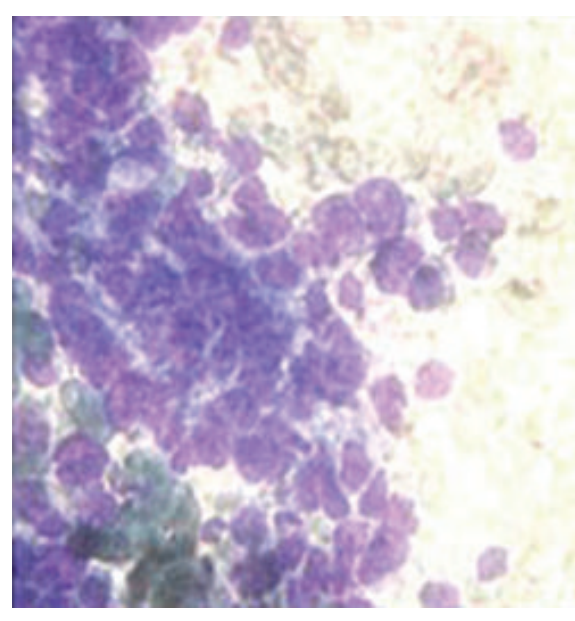

(a)

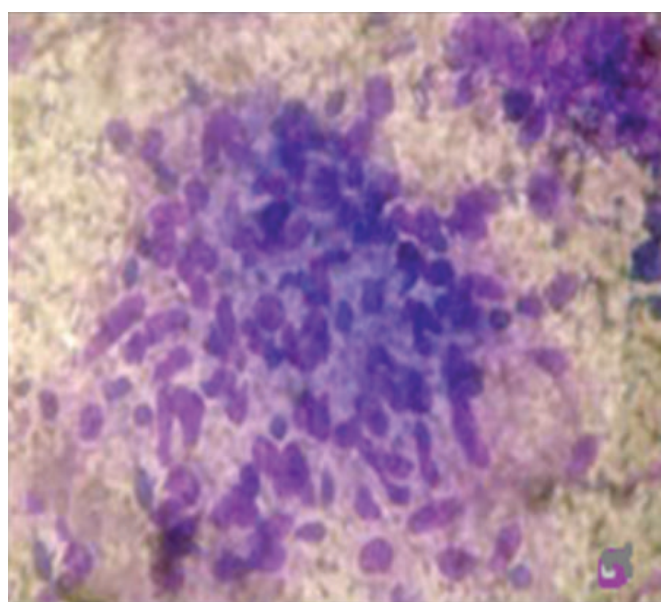

(b)

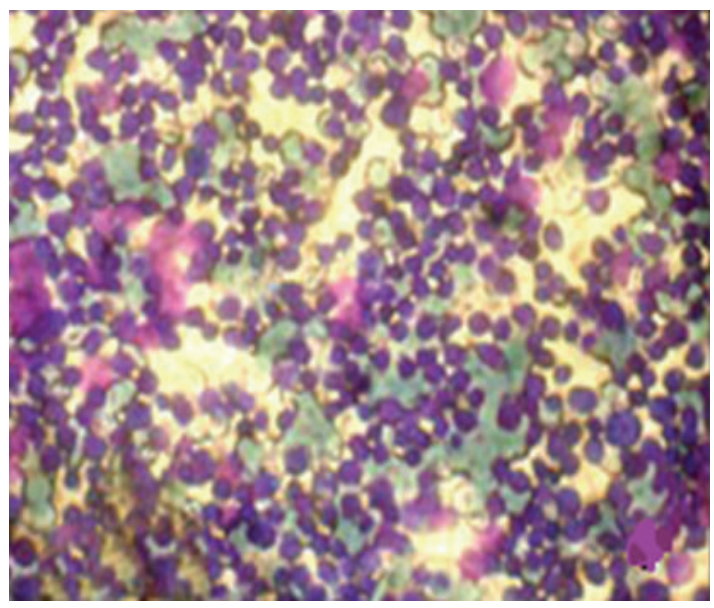

(c)

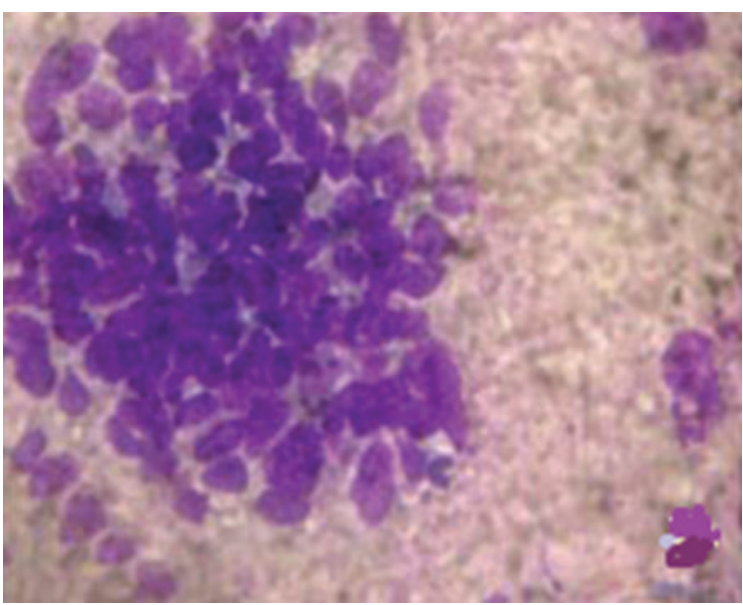

(d)

Figure 1: Cytomorphological appearances of various primary lung lesions. (a) Atypical cells of small cell carcinoma exhibiting nuclear moulding and smudging [MGG $\times 400]$. (b) Epithelioid cell collections forming granuloma [MGG $\times 200]$. (c) Monomorphic population of lymphoid cells in lymphoproliferative disorder [MGG $\times 200]$. (d) Atypical cells forming gland pattern in adenocarcinoma [MGG $\times 400]$.

with $2-17 \%$ requiring a chest tube $[24,25]$. In the present study, in only 2 cases, features of mild dyspnoea were noted which resolved within half an hour after procedure. No other significant postprocedural complication was reported.

An attempt was made in the present study to evaluate the degree of agreement between cytology and radiology which was found to be $89.2 \%$. Because cytology was considered as the gold standard, the accuracy of FNA diagnosis is going to be somewhat elevated as compared to studies wherein histology \pm immunostaining is used as the gold standard.

Although $100 \%$ cytoradiological concordance was noted in cases presenting with metastatic and mediastinal lesions, discordance was noted in five of the primary lung lesions. Three cases of primary malignant lesions of lung which were diagnosed as adenocarcinomas on radiology turned out to be squamous cell carcinomas on cytology. One case of a 60-yearold female, diagnosed as multricentric bronchogenic carcinoma on radiology, turned out to be granulomatous inflammatory kochs pathology on cytology. In the last instance of cytoradiological discrepancy, a reported malignant lesion in the case of a 68-year-old male on radiology turned out to be that of pyogenic abscess when aspirated. Culture growth yielded pseudomonas colonies. The lesion resolved completely with conservative measures. Four cases of lung lesions, which were diagnosed as malignant on radiology, were also reported as highly suspicious of malignancy on cytology. Taking into consideration both radiological and cytological findings, these patients were taken up by treating physicians as cases of primary carcinoma lung.

\section{Conclusions}

The present study thus concludes that CT-guided FNA in thoracic lesions is a simple, safe, and economically prudent technique associated with low morbidity, leading to quick and early diagnosis. Present study also concludes that it leads to an accurate diagnosis in conjunction with CT scan enabling direct visualization leading to greater degree of predicting true positive malignant cases. It should be used as a first line 


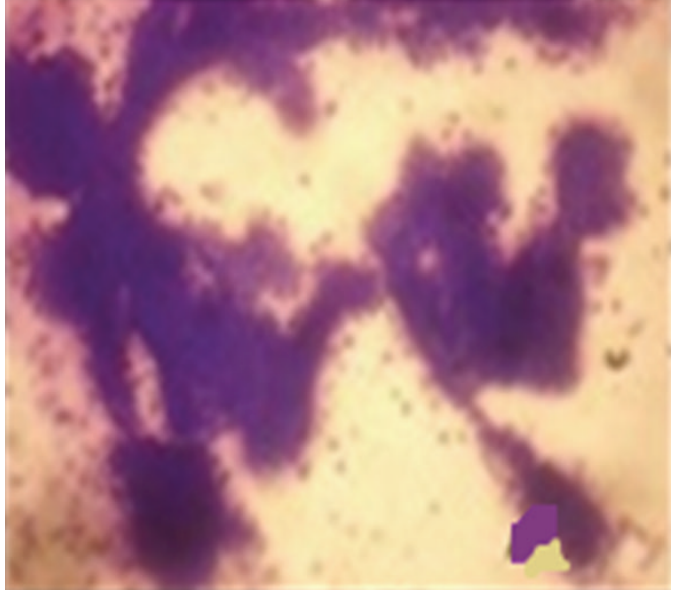

(a)

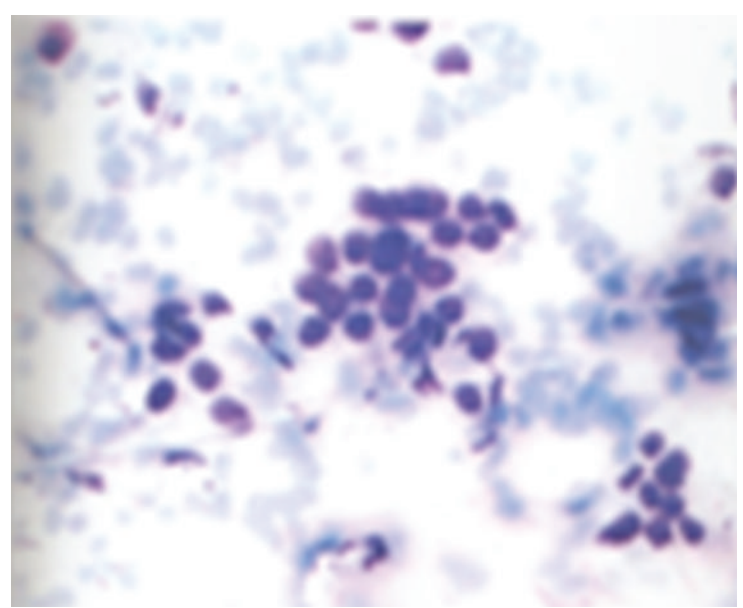

(b)

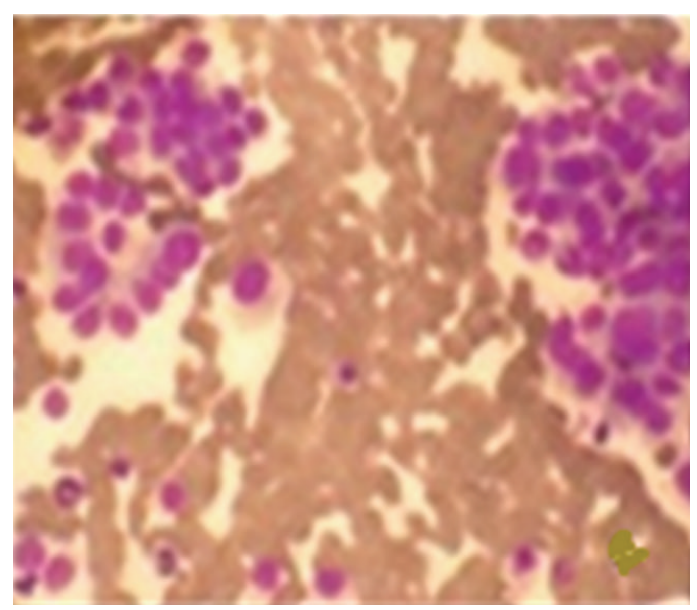

(c)

Figure 2: Cytomorphological findings in various metastatic lung lesions. (a) Metastasis of papillary fragments of adenocarcinoma arising from GIT [MGG ×200]. (b) Metastasis of squamous cell carcinoma arising from oral cavity [MGG ×400]. (c) Metastasis of follicular neoplasm thyroid $[\mathrm{MGG} \times 200]$.

investigation in cases of malignant thoracic lesions. Hence TTFNA of small pulmonary lesions helps in early diagnosis, improved staging, increased chance of effective intervention, and formulating immediate effective management of thoracic mass lesions.

\section{Conflict of Interests}

The authors declare that there is no conflict of interests regarding publication of this paper.

\section{References}

[1] W. D. Taris, Pathology and Genetics of Tumors of the Lung, Pleura, Thymus and Heart, IARC Press, Lyon, France, 2004, Edited by B. Brambilla, H. K. Muller-Hemrelink, C. C. Harris.

[2] S. Karki and S. Chalise, "Analysis of mediastinal lesions: a study of 27 cases," Journal of Pathology of Nepal, vol. 1, pp. 114-117, 2011.

[3] M. Gangopadhyay, I. Chakrabarti, N. Ghosh, and A. Giri, "Computed tomography guided fine needle aspiration cytology of mass lesions of lung: our experience," Indian Journal of Medical and Paediatric Oncology, vol. 32, no. 4, pp. 192-196, 2011.

[4] A. Saha, K. Kumar, and M. K. Choudhuri, "Computed tomography-guided fine needle aspiration cytology of thoracic mass lesions: a study of 57 cases," Journal of Cytology, vol. 26, no. 2, pp. 55-59, 2009.

[5] A. M. Salazar and J. L. Westcott, "The role of transthoracic needle biopsy for the diagnosis and staging of lung cancer," Clinics in Chest Medicine, vol. 14, no. 1, pp. 99-110, 1993.

[6] M. Rangaswamy, T. Zacharia, J. Krishnamurthy, G. Chennakeshaviah, S. Sunila, and M. Vimala, "Study of computed tomography-guided fine needle aspiration cytology of thoracic lesions," Journal of Cytology, vol. 29, no. 1, pp. 30-34, 2012.

[7] C. J. R. Stewart and I. S. Stewart, "Immediate assessment of fine needle aspiration cytology of lung," Journal of Clinical Pathology, vol. 49, no. 10, pp. 839-843, 1996.

[8] S. Kalhan, P. Sharma, S. Sharma, S. Dudani, T. Ramakrishnan, and A. Chowdhry, "Evaluation of precision of guidance techniques in image guided fine needle aspiration cytology of thoracic mass lesions," Journal of Cytology, vol. 29, no. 1, pp. 610, 2012. 
[9] P. T. Cagle, M. Kovach, and I. Ramzy, "Causes of false results in transthoracic fine needle lung aspirates," Acta Cytologica, vol. 37, no. 1, pp. 16-20, 1993.

[10] J. F. Silverman, J. L. Finley, K. F. O’Brien et al., "Diagnostic accuracy and role of immediate interpretation of fine needle aspiration biopsy specimens from various sites," Acta Cytologica, vol. 33, no. 6, pp. 791-796, 1989.

[11] D. J. Conces Jr., G. R. Schwenk Jr., P. R. Doering, and M. D. Glant, "Thoracic needle biopsy. Improved results utilizing a team approach.," Chest, vol. 91, no. 6, pp. 813-816, 1987.

[12] J. H. M. Austin and M. B. Cohen, "Value of having a cytopathologist present during percutaneous fine-needle aspiration biopsy of lung: report of 55 cancer patients and metaanalysis of the literature," The American Journal of Roentgenology, vol. 160, no. 1, pp. 175-177, 1993.

[13] R. J. Zarbo and C. M. Fenoglio-Preiser, "Interinstitutional database for comparison of performance in lung fine- needle aspiration cytology. A College of American Pathologists QProbe study of 5264 cases with histologic correlation," Archives of Pathology and Laboratory Medicine, vol. 116, no. 5, pp. 463470, 1992.

[14] D. Veale, J. J. Gilmartin, M. D. Sumerling, V. Wadehra, and G. J. Gibson, "Prospective evaluation of fine needle aspiration in the diagnosis of lung cancer," Thorax, vol. 43, no. 7, pp. 540-544, 1988.

[15] G. L. Weisbrod, D. J. Lyons, L. C. Tao, and D. W. Chamberlain, "Percutaneous fine-needle aspiration biopsy of mediastinal lesions," The American Journal of Roentgenology, vol. 143, no. 3, pp. 525-529, 1984.

[16] L. G. Koss and J. Zajieek, "Aspiration biopsy in koss," in Diagnostic Cytology and Histopthologic Basis, L. G. Koss, Ed., pp. 643-712, Philadelphia, Pa, USA, JB Lippincott company, 4th edition, 2005.

[17] J. Kowalewski, J. Sir, M. Dancewicz, J. Świniarska, and J. Pepliński, "Fine-needle aspiration biopsy under CT-scan guidancethe usefulness in diagnosis of malignant lung tumors," Pneumonologia i Alergologia Polska, vol. 72, no. 5-6, pp. 177-180, 2004.

[18] X. Wu, F. D. Groves, C. C. McLaughlin, A. Jemal, J. Martin, and V. W. Chen, "Cancer incidence patterns among adolescents and young adults in the United States," Cancer Causes and Control, vol. 16, no. 3, pp. 309-320, 2005.

[19] A. Mondal and M. C. Pradhan, "Role of percutaneous fine needle aspiration cytology (FNAC) in detection of lung, pleural and mediastinal tumours-a study of 162 cases," Indian Journal of Pathology and Microbiology, vol. 34, no. 4, pp. 253-258, 1991.

[20] H. Y. Pak, S. Yokota, R. L. Teplitz, S. L. Shaw, and J. L. Werner, "Rapid staining techniques employed in fine needle aspirations of the lung," Acta Cytologica, vol. 25, no. 2, pp. 178-184, 1981.

[21] L. C. Tao, D. E. Sanders, G. L. Weisbrod, C. S. Ho, and S. Wilson, "Value and limitations of transthoracic and transabdominal fine-needle aspiration cytology in clinical practice," Diagnostic Cytopathology, vol. 2, no. 4, pp. 271-276, 1986.

[22] M. F. Zakowski, R. M. Gatscha, and M. B. Zaman, "Negative predictive value of pulmonary fine needle aspiration cytology," Acta Cytologica, vol. 36, no. 3, pp. 283-286, 1992.

[23] P. Alonso, S. Sánchez, E. Ramírez, and R. Cicero, "Transthoracic needle biopsy in neoplastic and nonneoplastic pathology: experience in a general hospital.," Diagnostic cytopathology, vol. 2, no. 4, pp. 284-289, 1986.
[24] E. A. Kazerooni, F. T. Lim, A. Mikhail, and F. J. Martinez, "Risk of pneumothorax in CT-guided transthoracic needle aspiration biopsy of the lung," Radiology, vol. 198, no. 2, pp. 371-375, 1996.

[25] Prashant, C. Ramachandra, R. Pattbhariman, and S. S. V. Attili, "Feasibility, safety and efficacy of CT guided fine needle aspiration cytology of lung lesions," Indian Journal of Medical and Paediatric Oncology, vol. 28, no. 2, pp. 16-25, 2007. 


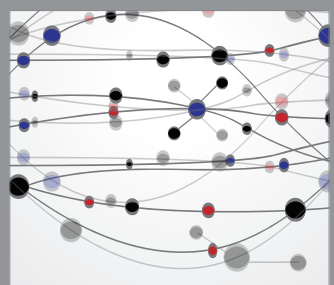

The Scientific World Journal
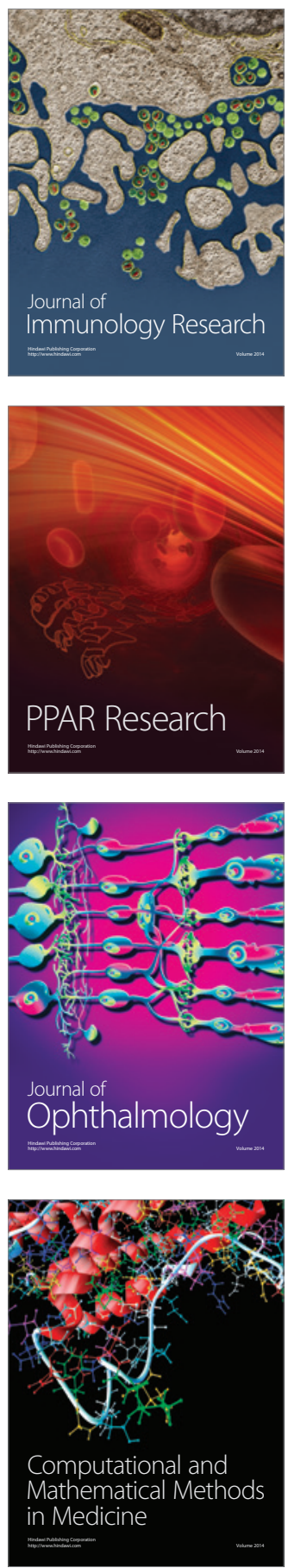

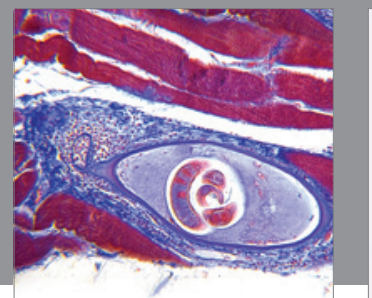

Gastroenterology

Research and Practice
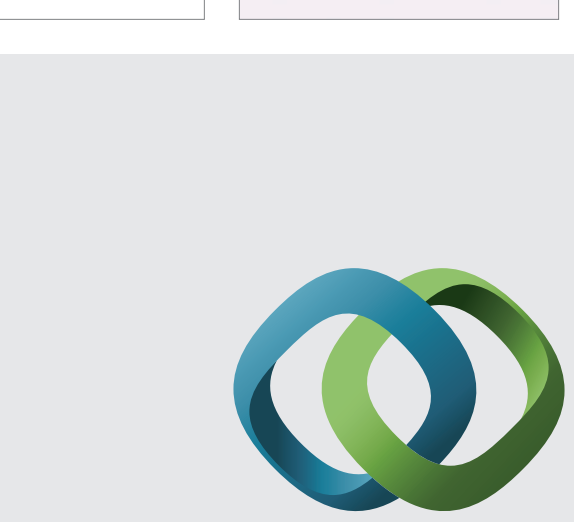

\section{Hindawi}

Submit your manuscripts at

http://www.hindawi.com
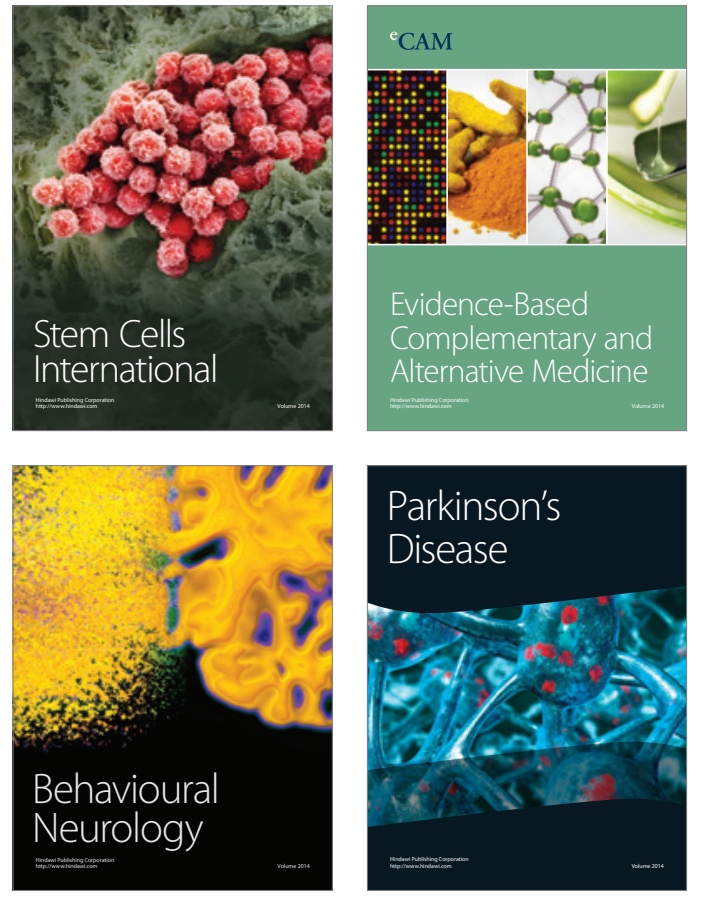
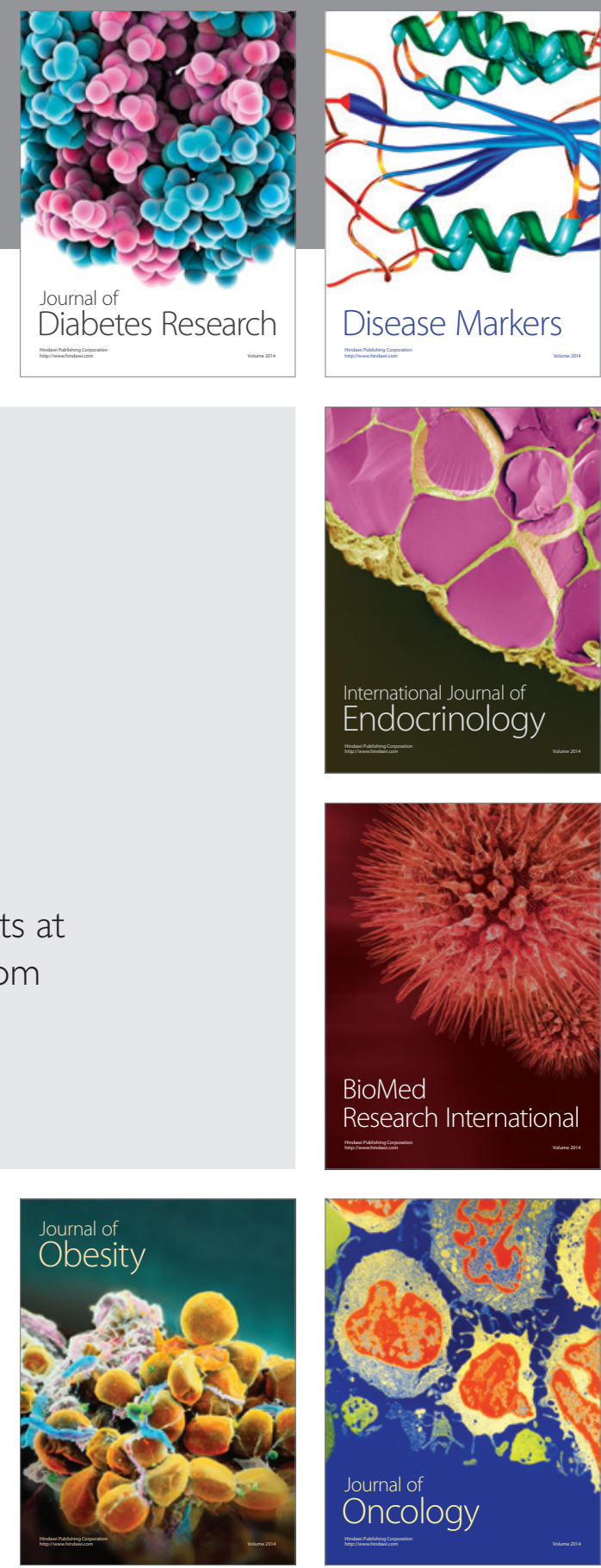

Disease Markers
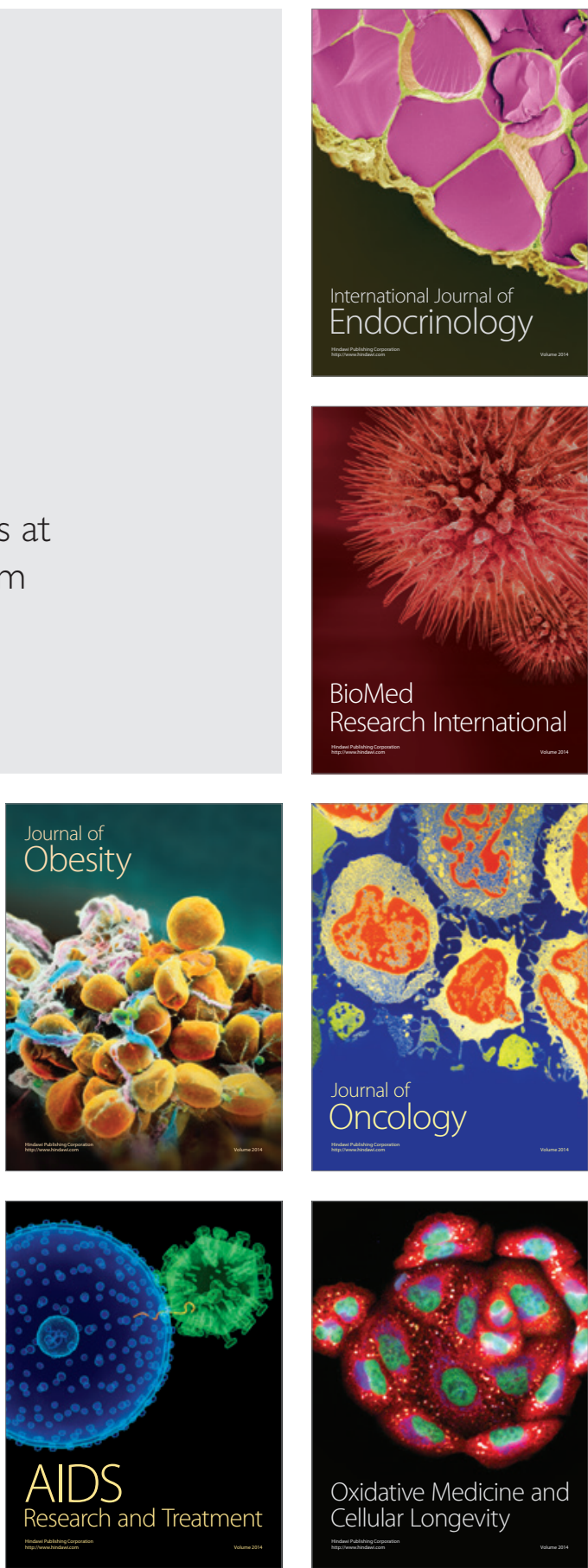